\title{
DIREITOS DOS RIBEIRINHOS NO BRASIL: CONSTRUÇÃO DE BARRAGENS A PANDEMIA COVID-19
}

\section{RIGHTS OF RIBEIRINHOS IN BRAZIL: CONSTRUCTION OF DAMS TO PANDEMIA COVID-19}

\section{DERECHOS DE RIBEIRINHOS EN BRASIL: CONSTRUCCIÓN DE PRESAS A LA PANDEMIA COVID-19}

\author{
Dorival Bonfá Neto ${ }^{1}$ https://orcid.org/0000-0001-7570-5441 \\ Bruno dos Santos Domingos ${ }^{2}$ https://orcid.org/0000-0002-4378-8825 \\ Inaiá Rossi Silva ${ }^{3}$ https://orcid.org/0000-0002-6130-5647
}

\begin{abstract}
${ }^{1}$ Doutorando em Ciências pelo Programa de Pós-graduação em Integração da América Latina da Universidade de São Paulo (PROLAM/USP). Bacharel e licenciado em Geografia pela Universidade de São Paulo. Professor de Geografia. E-mail: dorival.neto@usp.br.

${ }^{2}$ Graduando em Direito pela Faculdade de Direito Largo São Francisco da Universidade de São Paulo (FD/USP). E-mail: brunodomingos@usp.br.

${ }^{3}$ Graduanda em Relações Públicas pela Escola de Comunicação e Artes da Universidade de São Paulo (ECA/USP). E-mail: inaia.silva@usp.br.
\end{abstract}

\section{RESUMO}

Este trabalho tem como objeto de estudo as comunidades ribeirinhas (habitantes tradicionais das margens dos rios), acerca das quais busca-se compreender o que as caracteriza, quais são seus direitos e qual sua situação atual diante da crise da Covid-19 e das constantes ameaças à sua existência impostas por construções de barragens. O trabalho traz consigo um viés interpretativo crítico a respeito das garantias fundamentais destas comunidades que, eventualmente, encontram-se em xeque mediante atividades de cunho desenvolvimentistas por parte do Estado, como a construção de barragens para usinas hidrelétricas. Para analisar as problemáticas que envolvem essas questões fez-se necessário examinar os direitos assegurados dessas populações e o modo como eles são implementados. Para isso, através de um levantamento bibliográfico, identificamos as normas nacionais e internacionais que regem as relações entre a execução de projetos desenvolvimentistas e as populações tradicionais em específico, os ribeirinhos, e como essas populações vêm sendo afetadas pelas construções de barragens e, mais recentemente, pela pandemia da Covid-19. Dessa maneira, pudemos perceber que apesar de alguns avanços em relação à garantia dos direitos fundamentais de tais populações, o Estado ainda segue adotando políticas ineficientes para a preservação de seu modo de vida, fazendo com que sua existência seja, continuamente, ameaçada.

Palavras-chave: Ribeirinhos. Barragens de hidrelétricas. Covid-19.

\section{ABSTRACT}

This work is focused on the study of certain ribeirinhos communities (traditional inhabitants of the riverbanks and adjoining low lands areas), we sought to understand what characterizes them, what are 
their rights and what is their current situation in the face of the Covid-19 crisis and constant threats to their existence posed by a hydroelectrical power plant construction. The work was structured with a critical interpretive bias regarding the fundamental guarantees of these communities that, eventually, find themselves in check through developmental activities by the State, such as the construction of dams for hydroelectric plants. To analyze the issues surrounding these issues, it was necessary to examine the guaranteed rights of these populations and the way in which they are implemented. Hence, through a bibliographic survey, we identified the national and international norms that govern the relationship between the execution of development projects and traditional populations in particular, the riverside dwellers, and how these populations have been affected by the construction of dams and, more recently, by the Covid-19 pandemic. We could see that despite some advances in relation to guaranteeing the fundamental rights of such populations, the State still continues to adopt inefficient policies to preserve their way of life, causing their existence to be continually threatened.

Keywords: Ribeirinhos. Hydroelectric dams. Covid-19.

\section{RESUMEN}

Este trabajo tiene como objeto de estudio las comunidades ribereñas (habitantes tradicionales de las riberas), sobre las cuales buscamos entender qué las caracteriza, cuáles son sus derechos y cuál es su situación actual frente a la crisis del Covid-19 y las constantes amenazas a su existencia planteadas por la construcción de presas. El trabajo trae consigo un enfoque interpretativo crítico sobre las garantías fundamentales de estas comunidades que, eventualmente, se encuentran reprimidas a través de actividades de desarrollo por parte del Estado, como la construcción de presas para centrales hidroeléctricas. Para analizar los problemas que rodean estos temas, fue necesario examinar los derechos garantizados de estas poblaciones y la forma en que se implementan, através de un relevamiento bibliográfico, identificamos las normas nacionales e internacionales que rigen la relación entre la ejecución de proyectos de desarrollo y las poblaciones tradicionales en particular, los ribereños, y cómo estas poblaciones se han visto afectadas por la construcción de represas y, más recientemente, por la pandemia del Covid-19. Así, pudimos ver que a pesar de algunos avances en relación a garantizar los derechos fundamentales de dichas poblaciones, el Estado aún continúa adoptando políticas ineficientes para preservar su forma de vida, lo que hace que su existencia se vea continuamente amenazada.

Palabras-clave: Ribeirinhos. Represas hidroeléctricas. Covid-19.

\section{INTRODUÇÃO}

A imensidão do território brasileiro favoreceu que a sua ocupação se desse de maneira muito variada, pois além da diversidade de paisagens e domínios naturais, também houve uma grande miscigenação na população, consequência dos diversos e expressivos vínculos migratórios para o território brasileiro, onde se estabeleceram distintas maneiras de relação entre sociedade e natureza, que favoreceu a formação de sociedades tradicionais (LITTLE, 2002). Foi então se constituindo um modelo de ocupação do espaço e de utilização dos recursos naturais marcado pela influência de tradições indígena e portuguesa, que, ao longo do tempo, também recebeu grande influência das africanas e de outras europeias.

Como os europeus estavam frente a um espaço nunca antes visto, foi dos indígenas que eles apropriaram muitos dos recursos para a sobrevivência, como os alimentares e as técnicas e instrumentos de cultivo, caça e pesca (como o fabrico e uso de canoas, jangadas, 
redes e armadilhas). Isso garantiu a permanência dos europeus em um espaço com o qual não haviam tido relação anteriormente, fato que resultou em um povo novo, como afirma Darcy Ribeiro (2015, p.17).

Novo porque surge como uma etnia nacional, diferenciada culturalmente de suas matrizes formadoras, fortemente mestiçada, dinamizada por uma cultura sincrética e singularizada pela redefinição de traços culturais delas oriundos. Também novo porque se vê a si mesmo e é visto como uma gente nova, um novo gênero humano diferente de quantos existiam.

O contato do modo de vida do colonizador com o do indígena e posteriormente do negro, produz o que Antonio Candido chama de cultura rústica, termo que se refere às relações sociais e culturais e não somente por estarem localizadas no meio rural, mas que segundo Candido (2010, p.20):

[...] pretende exprimir um tipo social e cultural, indicando o que é, no Brasil, o universo das culturas tradicionais do homem no campo; as que resultaram do ajustamento do colonizador português ao Novo Mundo, seja por transferência e modificação dos traços de cultura original, seja em virtude do contato com o aborígine. Implicando, não obstante o isolamento, em constante incorporação e reinterpretação de traços, que vão-se alterando através do contínuo rural-urbano [...].

A característica cultural marcada pela miscigenação, ainda hoje, é presente em muitas comunidades no território do Brasil, chamadas de populações tradicionais ou povos tradicionais, que são caracterizadas, sobretudo, por “[...] viverem em áreas naturais onde a dependência do mundo natural, de seus ciclos e de seus produtos é fundamental para a produção e reprodução de seu modo de vida." (DIEGUES, 2005, p.1).

Dessa forma, a noção de população tradicional é utilizada para definir sociedades e comunidades que possuem um modo de vida e uma cultura distinta daquela predominante nas áreas urbano industriais. São sociedades que se reproduzem com relações mais isoladas, em que predomina o parentesco, a parceria, o trabalho coletivo e possuem relações próprias com a natureza, fruto de adaptações, tradicionalismos e de conhecimentos tradicionais, passados por gerações.

As sociedades tradicionais podem ser divididas em indígenas e não indígenas, estas possuem uma cultura onde há uma miscigenação mais recente em sua base, e contam com muitos aspectos da cultura indígena, como o modelo de ocupação do território, a utilização de recursos naturais e um modo de vida baseado no tempo natural. Entre as sociedades tradicionais não indígenas estão os ribeirinhos. Para essas sociedades tradicionais a pesca artesanal, o extrativismo e a pequena agricultura são elementos determinantes do modo de vida, do trabalho, e, portanto, da organização territorial (DIEGUES; ARRUDA, 2001). 
No Brasil, 650.234 famílias se declaram como povo ou comunidade tradicional, das quais cerca de $10 \%$ são ribeirinhas (PAULO, 2019). Dada sua enorme presença no país, sua importância sociocultural e as crescentes ameaças que se impõe sobre essas comunidades é urgente a elaboração de estudos e debates em torno das problemáticas que as permeiam, a fim de aclarar a situação desses povos no país, quais são seus direitos e como eles vem sendo, constantemente, desrespeitados.

Mapa 1 - Comunidades Ribeirinhas no Brasil

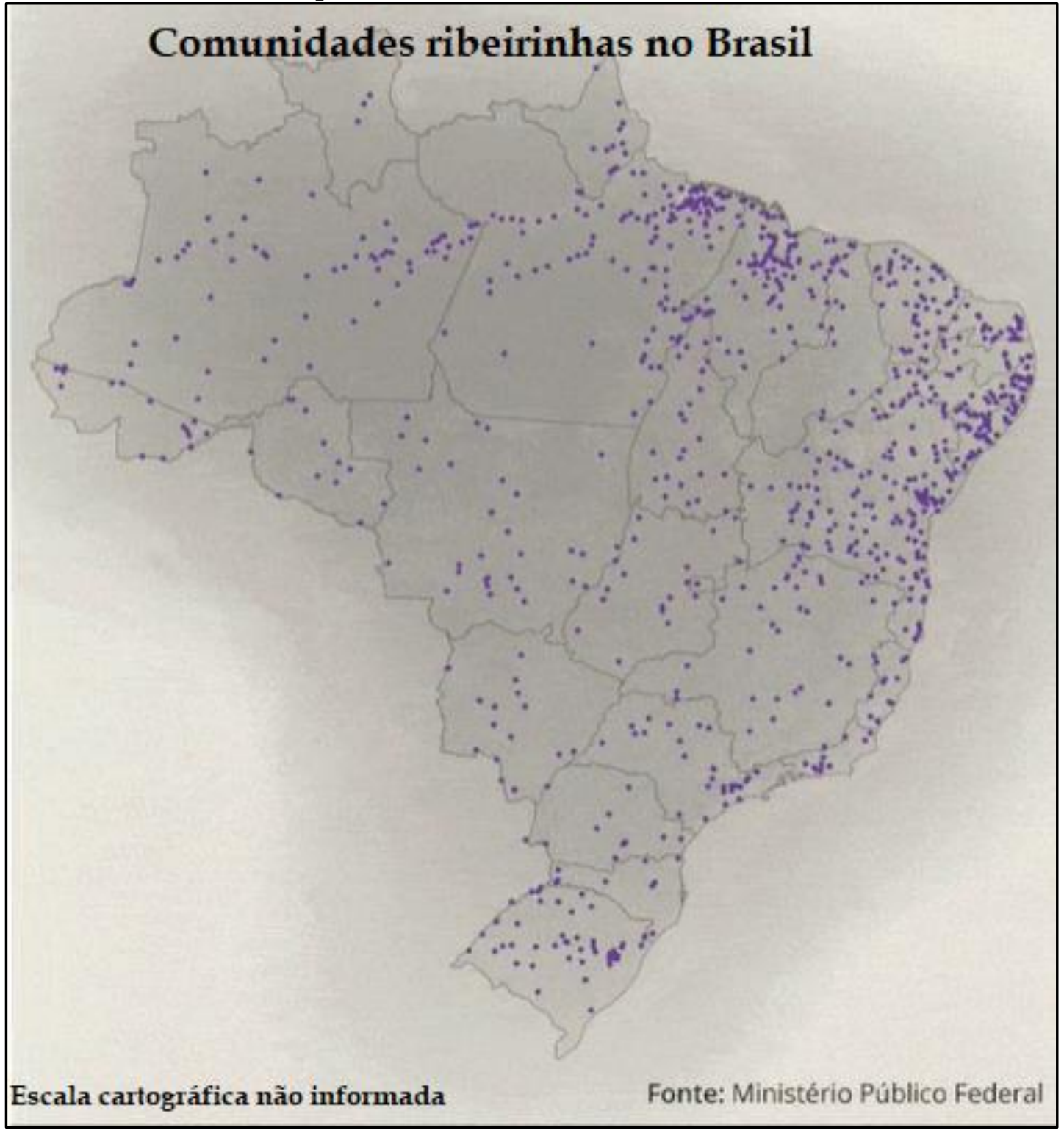

Fonte: Paula Paiva Paulo (2019). Editado pelos autores.

A constituição brasileira de 1988, garante às sociedades indígenas e quilombolas o direito coletivo ao território. Porém, outras populações tradicionais como os caiçaras, os ribeirinhos, os pantaneiros, os campeiros, os jangadeiros, entre outros, não possuem legislação que garanta a posse de suas terras ocupadas e, quando os seus direitos territoriais são garantidos, 
estes são definidos em termos de conservação ou preservação ambiental (LITTLE, 2002). Em muitos casos, também se observa que territórios indígenas e quilombolas ainda não foram demarcados, portanto, muitas vezes esses povos também não possuem a posse de suas terras.

Dado o atual cenário mundial, com a crise provocada pela pandemia da Covid-19, também se faz necessário discutir questões de acesso à saúde por parte das comunidades ribeirinhas, uma vez que a pandemia tem sido uma grande ameaça a esses habitantes (GAMA et al, 2018; CHAGAS, 2020; PINHEIRO JÚNIOR et al, 2020; RAMALHO et al, 2020), alastrando-se sobre eles com uma mortalidade muito elevada em relação ao restante do país (LIFSITCH, 2020).

Além disso, será abordada a implicação das barragens - ameaça constante à existência das comunidades ribeirinhas - visando expor o processo em prol da construção de hidrelétricas, de remoção e realocação dessas populações e analisar os impactos dessas construções na vida desses povos, conforme evidenciado por estudos de diversas áreas do conhecimento (VALENCIO; GONÇALVES, 2006; ALVES; JUSTO, 2009; WEIMANN, 2013; SANTOS, 2015).

Esse artigo traz consigo um viés interpretativo crítico a respeito das garantias fundamentais destas comunidades que, eventualmente, encontram-se em xeque mediante uma histórica política de inobservância aos povos tradicionais e áreas de proteção ambiental no Brasil, salvo, contudo, governos recentes, mais especificamente o período entre 2007 e 2015, que promoveram, ainda que de modo anódino, grandes avanços para com essas questões, como o Decreto nº6.040 de 2007 que instituiu a Política Nacional de Desenvolvimento Sustentável dos Povos e Comunidades Tradicionais, reconhecendo esses em suas múltiplas diversidades. $\mathrm{O}$ decreto definiu Comunidades e Povos tradicionais como sendo:

\section{[...] grupos culturalmente diferenciados e que se reconhecem como tais, que possuem formas próprias de organização social, que ocupam e usam territórios e recursos naturais como condição para sua reprodução cultural, social, religiosa, ancestral e econômica, utilizando conhecimentos, inovações e práticas, gerados e transmitidos pela tradição. (BRASIL, 2007).}

Sob a promessa de realização de projetos de cunho desenvolvimentistas por parte do Estado, os povos e comunidades tradicionais, entre eles os ribeirinhos, muitas vezes têm suas atividades produtivas e de subsistência, além de sua cultura e modo de vida, minadas por ações que afetam os territórios tradicionalmente ocupados por essas populações (ALVES; JUSTO, 2009; VALENCIO; GONÇALVES, 2006).

Isso coaduna com o fato de que, atualmente, na América Latina há o predomínio de um modelo de desenvolvimento agrário que se enquadra no processo de reprodução ampliada do 
capital, supervalorizando o repertório científico eurocêntrico e as técnicas ocidentais e desconsiderando o conhecimento e as técnicas próprias das comunidades tradicionais indígenas e não indígenas (DIEGUES, 2019; LITTLE, 2015; PORTO GONÇALVES; LEFF, 2015).

Nesse sentido, práticas de manejo dos recursos naturais, sejam elas agrícolas, extrativistas, pesqueiras, como os terraceamentos ${ }^{1}$, a adubação verde ${ }^{2}$ e algumas técnicas de pesca artesanal, antes praticadas pelas comunidades e povos tradicionais, foram totalmente desprezadas em função de monoculturas agrícolas, uso de químicos, pesca industrial etc., que promovem uma intensa exploração dos recursos dos países latino-americanos (e dos países subdesenvolvidos em geral).

Portanto, para analisar as problemáticas que envolvem essas e outras questões faz-se necessário, também, examinar os direitos assegurados dessas populações, bem como a maneira pela qual (e se) eles são implementados. Para isso, abordaremos marcos nacionais e internacionais que regem as relações entre a execução de projetos desenvolvimentistas e as populações tradicionais, como a Constituição Federal de 1988, a Política Nacional de Desenvolvimento Sustentável da Aquicultura e da Pesca (Lei n $\left.{ }^{\circ} 11.959 / 09\right)$, a Política Nacional de Desenvolvimento Sustentável dos Povos e Comunidades Tradicionais (Decreto nº.040/2007) e as demandas previdenciárias (a partir da adesão do Estado em reconhecer os ribeirinhos como pescadores artesanais), bem como tratados internacionais, como a Convenção 169 da OIT, entre outras. Essas normas serão alicerces pelos quais iremos fundamentar as devidas análises e explorar as adversidades, no intuito de buscar mecanismos para a garantia da proteção e da seguridade do trabalhador e das populações tradicionais, seus modos de vida e suas práticas.

\section{COMUNIDADES TRADICIONAIS: OS RIBEIRINHOS}

O Brasil, além de apresentar uma das maiores taxas de diversidade biológica do planeta, é também um dos países de maior diversidade sociocultural. Isso se sustenta, inclusive, por meio de relações simbióticas com a preservação dos povos tradicionais presentes no país, uma vez que essas populações desenvolveram diferentes formas de adaptação aos ambientes onde

\footnotetext{
${ }^{1}$ Terraceamento é uma técnica agrícola voltada para o plantio e para a conservação do solo, empregada em terrenos muito inclinados, controlando a erosão hídrica e permitindo o cultivo.

${ }^{2}$ A adubação verde é uma técnica agrícola que promove a reciclagem do solo a partir do plantio de determinadas espécies vegetais, que fornecem nutrientes e fertilizam o solo, principalmente aquelas espécies que são da família das leguminosas, gramíneas, crucíferas e de cereais.
} 
estão presentes, de forma que, também, sua diversidade se expressa por meio de profundos vínculos estabelecidos com esses territórios que ocupam (LITTLE, 2002).

Os territórios ocupados por povos tradicionais são derivados do legado de suas ricas e diversas culturas e de seus conhecimentos que remontam as formas ancestrais de ocupação do continente e suas relações com a diversidade ambiental (PORTO GONÇALVES; LEFF, 2015). O entendimento de "território" em se tratando do ambiente ocupado pelas comunidades tradicionais, portanto, transborda a noção do termo decorrente da geografia e da limitação física de uma nação, sendo importante, para sua completa compreensão, realizar a convergência entre os aspectos geográficos e culturais. Dessa maneira, ao se analisar o território de qualquer grupo é necessário considerar e avaliar o contexto específico em que o mesmo surgiu, foi defendido ou reafirmado (OLIVEIRA; MAGANHINI, 2019).

Além disso, essas populações possuem um rico repertório de conhecimentos que, em encontro com a diversidade biológica, constituem um patrimônio histórico dos povos e comunidades tradicionais, construídos com e não contra a natureza (PORTO GONÇALVES; LEFF, 2015). Esses saberes tradicionais, passados de geração em geração, normalmente por via oral, podem contribuir para a manutenção da biodiversidade dos ecossistemas (LITTLE, 2015).

Essa tese se confirma por meio da observação de que esses conhecimentos resultam de uma co-evolução dos povos com os ambientes naturais em que se constituem, o que permitiu a conservação de um equilíbrio e uma relação de simbiose entre ambos, onde a manutenção da cultura daquele povo está estritamente associada à conservação dos aspectos naturais de seu território (DIEGUES, 2019).

A importância do papel das comunidades tradicionais na preservação da biodiversidade do território brasileiro pode ser observada, ainda, contrapondo-se as formas de manejo desses povos à atividade agropecuária e à forma como essa é realizada em território nacional (LITTLE, 2015). Enquanto as ações dos grandes fazendeiros e grupos econômicos resultam num máximo de erosão genética, mesmo quando seguem "medidas conservacionistas", o modelo de uso dos recursos naturais desenvolvido por povos tradicionais, frequentemente, resulta em um máximo de conservação.

Mas afirmo que no plano de pequenos territórios como os dos povos indígenas, dos camponeses, dos ribeirinhos e outros grupos tradicionais, podemos dizer que a sustentabilidade está funcionando. Eles estão usando o meio ambiente de uma forma adequada e que tem uma durabilidade no tempo. Em geral, esses grupos usam modos extensivos de produção em vez de modos intensivos de produção, como é o caso de grandes monocultivos agrícolas que precisam de adubo, de químicos etc. São modos de utilização extensiva do ecossistema que permitem sua regeneração. São modos de adaptação fundamentados no uso de recursos renováveis em vez de recursos não renováveis que se esgotam após um só uso. Em muitos casos, essas experiências vigentes são uma revalorização de práticas tradicionais. (LITTLE, 2015, p.137). 
Ainda associada à diversidade sociocultural, observa-se, também, uma imensa diversidade fundiária no Brasil que inclui, além das terras indígenas e quilombolas, mais comumente conhecidas e as únicas já demarcadas, terras de babaçueiros, caboclos, caiçaras, caipiras, campeiros, jangadeiros, pantaneiros, pescadores artesanais, ribeirinhos, sertanejos, entre outros (LITTLE, 2002).

Esse grande leque de grupos é comumente categorizado sob diversos nomes "populações", "comunidades", "povos", "sociedades", "culturas" - acompanhadas ainda pelos seguintes adjetivos: "tradicionais", "autóctones", "rurais", "locais", "residentes". Neste trabalho, apenas por questão de padronização e seguindo a definição estabelecida pelo Decreto n6.040/2007, tais grupos serão abordados sob a denominação de "povos" e "comunidades" tradicionais. Essas populações, entretanto, ainda não possuem instrumentos de demarcação de suas terras, por vezes seus direitos territoriais são garantidos em termos de conservação ambiental, e, por isso, a vulnerabilidade delas a conflitos socioambientais é ainda maior.

Soma-se à essa falta de reconhecimento e demarcação dos territórios desses grupos o fato de que,

Os povos tradicionais dedicados à extração de recursos pesqueiros - os ribeirinhos e os pescadores - confrontam outro conjunto de obstáculos para o reconhecimento formal de suas áreas de ocupação e uso, uma vez que, em muitos casos, não são 'terras' que estão em questão, mas seções de um rio, de um lago ou do mar, gerando assim 'terras aquáticas ou marinhas' que não contam com uma legislação adequada que reconheça as particularidades dessa apropriação. (LITTLE, 2015, p.18-19).

Os povos tradicionais, como já mencionado, foram reconhecidos no Brasil pelo Decreto nº.040/2007, por meio do qual o Governo Federal atribui a eles uma definição formal, reconhecendo a sua existência e as especificidades de sua forma de vida por meios jurídicos. $\mathrm{O}$ reconhecimento desses povos já havia sido feito de forma parcial na Constituição de 1988, contemplando apenas indígenas e quilombolas, de modo que somente vinte anos mais tarde passa, portanto, a abranger os demais povos com o referido decreto. O Decreto de 2007 instituiu a Política Nacional de Desenvolvimento Sustentável dos Povos e Comunidades Tradicionais, que tem por objetivos, entre outros:

I - garantir aos povos e comunidades tradicionais seus territórios, e o acesso aos recursos naturais que tradicionalmente utilizam para sua reprodução física, cultural e econômica; II solucionar e/ou minimizar os conflitos gerados pela implantação de Unidades de Conservação de Proteção Integral em territórios tradicionais e estimular a criação de Unidades de Conservação de Uso Sustentável; III - implantar infraestrutura adequada às realidades socioculturais e demandas dos povos e comunidades tradicionais; IV - garantir os direitos dos povos e das comunidades tradicionais afetados direta ou indiretamente por projetos, obras e empreendimentos; [...] VII - garantir aos povos e comunidades tradicionais o acesso aos serviços de saúde de qualidade e adequados às suas características socioculturais, suas necessidades e demandas, com ênfase nas concepções e práticas da medicina tradicional; [...] IX - criar e implementar, urgentemente, uma política pública de 
saúde voltada aos povos e comunidades tradicionais; X - garantir o acesso às políticas públicas sociais e a participação de representantes dos povos e comunidades tradicionais nas instâncias de controle social [...] (BRASIL, 2007).

Entre os povos tradicionais existentes, estão os ribeirinhos, povos que vivem à beira de igarapés, igapós, lagos e várzeas e são considerados não-indígenas. Essas populações surgiram da miscigenação decorrente do processo de colonização do país, além de processos migratórios mais recentes e que não possuem uma história sociocultural anterior e distinta da sociedade nacional e nem língua própria (DIEGUES; ARRUDA, 2001).

Paula Paiva Paulo (2019), mostra que o estado do Pará concentra o maior número de famílias ribeirinhas, sendo cerca de 50.314, seguido do Amazonas, com 16.507 e Bahia, com 9.670 famílias. Um relatório da Organização das Nações Unidas para a Alimentação e a Agricultura (FAO, 2020a), afirma a importância da atividade pesqueira nos rios do Brasil, sobretudo nos grandes rios e seus afluentes, como o Amazonas e o São Francisco, essa importância é destacada devido a pesca fortalecer a segurança alimentar dessas comunidades ribeirinhas, muitas delas com baixos recursos financeiros.

As comunidades ribeirinhas são compostas por uma mistura de diferentes grupos sociais e étnicos (indígenas, nordestinos e migrantes de outras regiões). Dentre suas principais atividades estão a pesca, caça, agricultura de subsistência, especialmente do cultivo da mandioca para a produção de farinha e o extrativismo da castanha e açaí, como também outros produtos naturais obtidos na floresta e comercializados nos arredores das comunidades.

Sua produção acontece em regime familiar, onde o excedente é comercializado e, em períodos de maior demanda de força de trabalho, ajudam-se mutuamente entre vizinhos. As atividades extrativistas realizadas variam conforme o ciclo das cheias e secas dos rios. Os ribeirinhos, ainda, possuem conhecimento da várzea, do rio e da mata, o que os permite tirar proveito dessas coletando alimentos, fibras, tinturas, resinas, ervas medicinais, além de materiais de construção (DIEGUES; ARRUDA, 2001).

Os ribeirinhos vivem em comunidades geralmente com laços familiares, compartilhando costumes como hábitos alimentares e manejo da terra. Não há padrão de ocupação do espaço e as comunidades diferem em relação à infraestrutura dado que algumas possuem energia elétrica, telefonia e antenas parabólicas, porém boa parte não dispõe de tais recursos, nem de sistema de saneamento básico ou de um atendimento adequado à saúde. Esses povos, portanto, dependem dos serviços e recursos da sede municipal e o seu deslocamento até a área urbana geralmente é feito por meio de canoas com motor (rabeta), o que, a depender da 
distância, tipo de transporte ou período do ano (seca ou cheia), pode demorar de minutos a dias (GAMA et al, 2018).

\section{DIREITOS DOS POVOS E COMUNIDADES TRADICIONAIS}

O reconhecimento formal por meios jurídicos dos povos e comunidades tradicionais, reivindicado por diferentes movimentos sociais e afirmado no texto constitucional de outubro de 1988 e complementado por demais decretos, conheceu um incremento neste início do século XXI e final de século XX. As ações de mobilização perpetradas pelos movimentos foram fortalecidas por medidas implementadoras dos dispositivos constitucionais, como as leis e políticas públicas nacionais além de tratados e convenções internacionais.

Acrescenta-se, também, aos efeitos destes dispositivos, principalmente em se tratando da legislação internacional a respeito dos direitos desses povos, o reforço de instrumentos elaborados por agências multilaterais, tais como: Organização das Nações Unidas (ONU), Organização das Nações Unidas para a Educação, a Ciência e a Cultura (UNESCO) e Organização Internacional do Trabalho (OIT) (BRAGA, 2016; NETO, 2007).

Acerca desta questão, é importante reiterar que o Decreto n6.040/2007, bem como a Constituição Federal de 1988, popularmente conhecida como "Constituição Cidadã", reconhecem formalmente a existência dos povos e comunidades tradicionais. Entretanto, o reconhecimento dessas populações não significa dizer que seus direitos, na prática, estão plenamente assegurados.

Nesse sentido, faz-se necessário, também, analisar tais direitos, bem como o modo como eles são implementados. Sobre isso, temos alguns outros marcos institucionais nacionais que garantem ou propõe a garantia a esses direitos, como a Política Nacional de Desenvolvimento Sustentável dos Povos e Comunidades Tradicionais, já citada, e a Política Nacional de Desenvolvimento Sustentável da Aquicultura e da Pesca, disposta pela Lei no 11.959/09, que garante os direitos previdenciários a essas populações, a partir da adesão do Estado em reconhecer os ribeirinhos como pescadores comerciais.

Em âmbito internacional temos a Convenção 169 da Organização Internacional do Trabalho (OIT, 1989), a Convenção Relativa à Proteção do Patrimônio Mundial, Cultural e Natural (1972). Esses marcos são alicerces que possibilitam fundamentar as devidas análises e explorar as adversidades, no intuito de, assim como o inciso segundo do Art. $5^{\circ}$ da Lei $n^{\circ}$ 11.959/09, assegurar, na melhor das hipóteses, "a busca de mecanismos para a garantia da proteção e da seguridade do trabalhador e das populações com saberes tradicionais”. 
Em relação aos direitos internacionais dos povos tradicionais, o primeiro passo para uma reflexão acerca deles é explicitar a sua forma jurídica, situando as Declarações e Convenções Internacionais no interior do sistema brasileiro a fim de melhor compreender sua funcionalidade dentro de nossa jurisdição. Nesse sentido, enquanto as Declarações servem como "princípios jurídicos" (conjunto de padrões de conduta presentes de forma explícita ou implícita no ordenamento jurídico) que orientam instrumentos e ações, as Convenções, por serem Tratados, geram obrigações, vinculando os países na ordem internacional e impondo sanções em caso de descumprimento das normas acordadas por meio destes (NETO, 2007).

O reconhecimento internacional da importância de se preservar os povos e comunidades tradicionais foi o que motivou essa busca por instrumentos legais para tal, passando por duas questões centrais: a primeira, dos conhecimentos tradicionais que, em sede internacional, dão ensejo a discussões envolvendo, por exemplo, propriedade intelectual e patrimônio genético, e a segunda, tratando da exploração sustentável de recursos naturais e da preservação do território natural (NETO, 2007).

A questão dos direitos desses povos, portanto, vem sendo tratada pelas normas internacionais que, com grande consistência de fundamentos e de validade, estabelecem mecanismos de proteção jurídica aos diversos elementos culturais, materiais e imateriais, que permeiam a existência dos povos tradicionais, como a Convenção 169 da OIT, a Convenção Relativa à Proteção do Patrimônio Mundial, Cultural e Natural e a Convenção sobre Diversidade Biológica (BRAGA, 2016).

A Convenção 169 sobre Povos Indígenas e Tribais, da Organização Internacional do Trabalho (OIT), órgão da Organização das Nações Unidas (ONU), foi adotada em Genebra, em 27 de junho de 1989, e entrou em vigor internacionalmente em 5 de setembro de 1991. No Brasil, o cumprimento dessa Convenção foi determinado pelo Decreto Presidencial n. ${ }^{\circ} 5.051$, de 19 de abril de 2004.

Por "povos indígenas ou tribais", a Convenção refere-se a povos culturalmente tradicionais que apresentem condições sociais, culturais e econômicas que se distinguem de outros segmentos da população nacional, tratados no presente trabalho por "povos tradicionais". $\mathrm{O}$ documento também reconhece o direito de posse e propriedade, preceituando medidas a serem tomadas para a salvaguarda destes direitos, estabelecendo que os Estados nacionais devem criar mecanismos que promovam a plena efetividade dos direitos sociais, econômicos e culturais desses povos, respeitando a sua identidade social e cultural, os seus costumes e tradições, e as suas instituições. Além disso, esse célebre acordo exige que os povos sejam consultados sobre qualquer assunto que os afetem (OIT, 1989). 
A Convenção Relativa à Proteção do Patrimônio Mundial, Cultural e Natural foi realizada em Paris em 23 de novembro de 1972, promulgada no Brasil pelo Decreto $\mathrm{n}^{\circ}$ 80.978, de 12 de dezembro de 1977, e aprovada pelo Congresso Nacional, através do Decreto Legislativo $n^{\circ} 74$ de 30 de junho de 1977. Ela estabelece mecanismos de reconhecimento e proteção de estruturas com destacado interesse para a humanidade e demonstra a importância que representa, para todos os povos do mundo, a salvaguarda desses bens incomparáveis e insubstituíveis, qualquer que seja o povo a que pertençam.

Este documento verifica que os patrimônios cultural e natural são cada vez mais ameaçados de destruição e considera que a degradação ou o desaparecimento de um bem desses patrimônios constitui um empobrecimento nefasto do patrimônio de todos os povos do mundo, além de ressaltar que a proteção desses patrimônios em escala nacional é frequentemente incompleta. Entre as definições dadas para Patrimônio Cultural e Natural, é de nosso principal interesse o que consta no Parágrafo 3, Artigo 2, que define como patrimônio natural “Os lugares notáveis naturais ou as zonas naturais nitidamente delimitadas, que tenham valor universal excepcional do ponto de vista da ciência, da conservação ou da beleza natural." (Convenção para a Proteção do Patrimônio Mundial, Cultural e Natural, 1972, p. 2).

A despeito disso, em 2003 a Unesco (Organização das Nações Unidas para a Educação, Ciência e Cultura) passou a reconhecer um conjunto de Unidades de Conservação (UCs), localizadas no estado do Amazonas, como Sítio do Patrimônio Natural da Humanidade. O conjunto inclui o Parque Nacional do Jaú (2,272 milhões de hectares, que já tinha o status de sítio do patrimônio desde 2000), a Reserva de Desenvolvimento Sustentável de Amanã (2,350 milhões de hectares, a Estação Ecológica de Anavilhanas (350 mil hectares, no Rio Negro) e parte da Reserva de Desenvolvimento Sustentável de Mamirauá (260 mil hectares). O novo sítio passou a ser reconhecido como Complexo de Conservação da Amazônia Central (UNESCO, 1999). Seu reconhecimento como Patrimônio Natural da Humanidade implica em uma maior responsabilidade do Estado com tais unidades de conservação, dada a Convenção Relativa à Proteção do Patrimônio Mundial, Cultural e Natural, e, portanto, com as populações que tradicionalmente as ocupam. Na região do Médio Solimões, na Amazônia Central, as reservas de Mamirauá e Amanã abrigam cerca de 16 mil pessoas, sendo que aproximadamente metade são ribeirinhos.

Outro marco de extrema importância é a Convenção sobre Diversidade Biológica (CDB), assinada no Rio de Janeiro, em 5 de junho de 1992, promulgada pelo Decreto $\mathrm{n}^{\circ} 2.519$, de 16 de março de 1998, e aprovada pelo Congresso Nacional, através do Decreto Legislativo $\mathrm{n}^{\circ} 2$ de 03 de fevereiro de 1994. A convenção abarca tudo o que se refere direta ou indiretamente 
à biodiversidade e, portanto, prevê a proteção de povos e comunidades tradicionais uma vez que as práticas de manejo dessas comunidades e sua relação com o ambiente que tradicionalmente ocupam são fundamentais para a conservação da diversidade biológica (CDB, 1992).

A CDB está estruturada sobre três bases principais: conservação da diversidade biológica, uso sustentável da biodiversidade e a repartição justa e equitativa dos benefícios provenientes da utilização dos recursos genéticos. A biodiversidade é colocada em três níveis: ecossistemas, espécies e recursos genéticos (NETO, 2007).

Acerca disso, prevê o respeito, preservação e manutenção de conhecimentos, inovações e práticas dos povos tradicionais relevantes à conservação e à utilização sustentável da diversidade biológica. Além de demandar a proteção e encorajar a utilização costumeira de recursos biológicos de acordo com as práticas culturais tradicionais compatíveis com as exigências de conservação e utilização sustentável, práticas que estão de acordo com a relação de simbiose com a natureza, de respeito aos ciclos naturais e aos recursos naturais renováveis mantida pelas comunidades tradicionais (CDB, 1992).

A respeito das leis brasileiras que possuem como escopo salvaguardar o direito do referido povo tradicional em exame, temos algumas já mencionadas: o Art. $5^{\circ}$ da Constituição Federal de 1988; o Decreto n. ${ }^{\circ}$ 6040/07 que reconhece, em amparo ao ordenamento anterior, a existência formalizada de tais grupos; e a Política Nacional de Desenvolvimento Sustentável da Aquicultura e da Pesca, disposta pela Lei no 11.959/09, importantíssima para o reconhecimento, ao menos formal, das demandas previdenciárias, classificando alguns ribeirinhos como Pescadores comerciais, passíveis de receberem os benefícios previdênciários e o Seguro Defeso.

Acerca dessa questão, há outros ordenamentos tão pertinentes quanto. Entre estes, vem à baila os seguintes marcos institucionais: a Lei $\mathrm{n}^{\mathrm{o}}$ 12.334, de 20 de setembro de 2010, que estabelece a "Política Nacional de Segurança de Barragens" (PNSB) e cria o Sistema Nacional de Informações sobre Segurança de Barragens, extremamente importante para as nefastas questões devidamente exploradas neste presente trabalho; a Lei n. ${ }^{\circ} 12.608$, de 10 de abril de 2012, que estabelece a "Política Nacional de Proteção e Defesa Civil" (PNPDEC) abarcando, também, como deve ser, os cidadãos pertencentes aos povos tradicionais; e a Lei $\mathrm{n}^{\circ} 10.678$, de 23 de maio de 2003, que promove a "Secretaria Especial de Políticas de Promoção da Igualdade Racial”, tema também atrelado ao povo ribeirinho, como o "Estatuto da Igualdade Racial”, este mais popular; dentre outros ordenamentos, sejam eles de categoria estadual, municipal ou de âmbito federal. 


\section{PROBLEMAS ENFRENTADOS PELOS RIBEIRINHOS: A QUESTÃO DAS BARRAGENS, ACESSO À SAÚDE E A PANDEMIA DA COVID-19}

Com a colonização dos portugueses, a Amazônia, que inicialmente era ocupada por povos indígenas, teve seus habitantes originais reduzidos devido a escravidão imposta pelos colonizadores e doenças como gripe, sarampo e tuberculose, também trazidas pelos portugueses (RIBEIRO, 2015). A construção da ferrovia Madeira-Mamoré e o ciclo da borracha (final do séc. XIX e início do séc. XXI), por sua vez, trouxeram um maior volume de pessoas à região, tornando sua população miscigenada e maior, o que deu origem a novas formas de organizações sociais, entre elas as comunidades ribeirinhas (GONÇALVES; DOMINGOS, 2019).

Observa-se que, já desde esse período, a região sofre com falta de acesso a serviços públicos, como saúde, educação e saneamento básico, que se concentravam nos grandes centros urbanos. Os problemas de saneamento e de saúde oriundos do período de colonização se mantêm até hoje.

Segundo Diniz et al (2007), a população dos estados que compõem a floresta Amazônia mantém níveis de pobreza muito elevados e baixa qualidade de vida, se comparados com a média nacional, o que pode ser verificado, entre outros indicadores, pelo Índice de Desenvolvimento Humano da região. Os nove estados que compõem a região amazônica têm um Índice de Desenvolvimento Humano (IDH) abaixo dos 0,750 enquanto a média do Brasil é de 0,778 (DINIZ et al, 2007).

Entre os afetados por tais condições que se estabelecem na região amazônica, observase que os povos ribeirinhos, de modo geral, são destituídos de infraestrutura mínima de saneamento básico, energia elétrica e serviços de saúde como Unidades de Básicas de Saúde e Unidades de Pronto Atendimento. A assistência à saúde é centralizada na zona urbana dos municípios, com ações esporádicas dos profissionais de saúde nas comunidades. Além disso, o clima equatorial, a floresta de imensas dimensões e as ações desenvolvimentistas operadas na região, constituem fatores singulares para o desenvolvimento de agravos de saúde típicos da região amazônica (GAMA et al, 2018).

Um inquérito realizado em 2015 com populações ribeirinhas do município de Coari (Amazonas) ajuda a comprovar tal situação ao verificar que a maioria dos ribeirinhos apresenta em média renda familiar mensal equivalente a 1/3 do salário-mínimo, além de que navegam em média $60,4 \mathrm{~km}$ e demoram cerca de 4,2 horas para acessar a zona urbana do município, onde se concentram os serviços básicos (GAMA et al, 2018). 
No cenário atual, de pandemia da Covid-19, esses problemas logísticos e de dificuldade de acesso à saúde por parte dos povos ribeirinhos configuraram um agravante no combate à doença, uma vez que o acesso à assistência médica é limitado (CHAGAS, 2020). Apesar de considerados isolados, os ribeirinhos da Amazônia estão intensamente conectados às áreas urbanas por meio da extensa rede hidrográfica da região, que mantém vínculos econômicos e de acesso a serviços essenciais e que, portanto, expõe essas populações a agentes externos, como o vírus SARS-CoV-2.

Segundo dados divulgados em maio de 2020, cerca de dois meses após a confirmação do primeiro caso de Coronavírus no Amazonas, a doença já havia chegado a $88 \%$ dos municípios do estado mesmo apesar das longas distâncias entre eles, poucas estradas e o decreto que proibia o transporte fluvial durante a pandemia (LIFSITCH, 2020). Essa situação é especialmente crítica no estado uma vez que as cidades do interior não são equipadas com leitos de UTI e todos os leitos de categoria de terapia intensiva na capital do estado, Manaus, foram rapidamente ocupados.

Acerca disso, não apenas o contágio da doença ocorre de forma acelerada, mas sua mortalidade também é mais alta dentre os povos tradicionais da região, como os ribeirinhos, que também tiveram o atendimento à saúde reduzido pela pandemia, devido a reduções das visitas dos profissionais da saúde às comunidades (CHAGAS, 2020).

De acordo com a FAO (2020a, 2020b), a pesca artesanal é uma das atividades mais afetadas pela pandemia da Covid-19, pois as medidas e restrições de circulação necessárias que foram tomadas pelos países afetaram toda a cadeia de produção, circulação, comercialização e consumo dos pescados. Nesse sentido, as comunidades que dependem da atividade foram intensamente afetadas devido a fatores como a crise nos sistemas de transportes para a exportação e importação de pescados e a incapacidade dos pescadores artesanais e de pequena escala em vender as suas produções, além da queda dos preços e da renda (FAO, 2020b).

Esses impactos se deram através das mudanças nas demandas dos consumidores, de problemas com o acesso aos mercados e problemas logísticos como o aumento do custo e a falta de abastecimento, fechamentos das fronteiras, falta de acesso a mercadorias como gelo, estocagem de pescados por muito tempo, queda e oscilações dos preços dos produtos da pesca (FAO, 2020b). Como consequências desses problemas houve uma perda de renda, a segurança alimentar foi impactada, e o acesso a comunicação, energia elétrica e combustível ficou mais restrito (CHAGAS, 2020).

Outro problema de grande relevância que afeta as comunidades ribeirinhas é a construção de barragens para usinas hidrelétricas, que modificam os cursos hídricos dos locais 
onde se instalam, impactando todo o modo de vida dos ribeirinhos, principalmente as atividades da pesca artesanal e da agricultura. Esse impacto é socioambiental, pois altera os ecossistemas locais e os territórios tradicionais, muitas vezes sendo os ribeirinhos expropriados de seus territórios ocupados ancestralmente (VALENCIO; GONÇALVES, 2006; ALVES; JUSTO, 2009; WEIMANN, 2013; SANTOS, 2015).

Observa-se então uma problemática muito evidente com relação a isso. Sob tal situação, nota-se a retirada de inúmeros direitos dos povos e das comunidades tradicionais ao passo que a implementação dos projetos de barragens de hidrelétricas solapam os interesses dessas populações, as quais acabam sendo forçadas a se retirarem da dada localidade, inviabilizando seus modos de vida tradicionais, isto é, impossibilitando as relações sociais e de produção da maneira como antes eram realizados.

Em um levantamento bibliográfico feito por Bonfá Neto e Suzuki (2019), a construção de barragens para usinas hidrelétricas foi colocada entre um dos principais fatores que causam conflitos socioambientais com comunidades de pescadores. Sobre a construção de barragens e polos hidrelétricos, Oliveira e Magnani (2019, p.43) afirmam que "[...] representam uma das maiores intervenções já realizadas pelo homem, com impactos em vários níveis econômicos, ambientais, culturais e sociais, que alteram de forma irreversível a constituição do meio ambiente no entorno da obra.".

Nesse sentido, a exigência de consulta prévia às comunidades sobre questões que as afetarão deixou de ser cumprida, também, em um momento crucial: da pandemia do Novo Coronavírus, durante a qual observou-se uma longa demora por parte do governo em consultar lideranças de comunidades tradicionais quanto às melhores formas de combater o avanço do vírus nas regiões ocupadas por essas populações (FUNAI, 2020), agravando, assim, a situação dessas comunidades frente à pandemia.

A data 14 de março poderia ser qualquer outra formalidade presente no calendário. Entretanto, ela representa o "Dia Internacional de Luta Contra as Barragens" (MAB, 2011), instituída pela "Declaração de Curitiba", fruto de uma união de lutas internacionais de mais de 20 países, representados por comunidades tradicionais atingidas por essa problemática mundo afora. Observa-se, portanto, que esse problema não se configura como exclusivo do Brasil. Contudo, vislumbra-se aqui agravantes estruturais extremamente danosos à essas populações residentes em território nacional (SANTOS, 2015).

A respeito disso, é válido mencionar, que essa problemática se fundamenta na construção de usinas hidrelétricas, as quais são necessárias o erguimento de dantescas barragens estruturais, no intuito de converter o imenso fluxo de água, essencialmente provocado pelo 
extenso alagamento de dadas áreas (finalidade das barragens), em energia elétrica. Com relação a isso, tal empreitada configura-se como a principal matriz energética do Brasil, classificada normalmente como "ecológica" ou "sustentável".

No tocante a essa questão, por ser considerada energia renovável e limpa ${ }^{3}$, há uma certa convenção falaciosa de que esse tipo de projeto não gera impactos danosos à natureza. Entretanto, vislumbra-se, como dito anteriormente, que as diversas barragens construídas afetam as comunidades ali residentes, afligindo seus modos de vida e, com isso, corroborando em danos à sua subsistência e, sobretudo, à sua cultura, bem como demais problemáticas atreladas ao ecossistema presente à localidade que se tem modificada, a ponto de existir um movimento social para evidenciar tais adversidades, o "Movimento de Atingidos por Barragens" (MAB). A respeito deste, sua relevância é tamanha que acaba configurando no segundo maior movimento social do país, atrás apenas do "Movimento dos Trabalhadores Rurais sem Terra" (MST). Sob tal ótica, mesmo essas hidrelétricas gozando de energia renovável para seu funcionamento, elas acabam provocando impactos irreversíveis às regiões em que se instalam.

Dessa maneira, é visível o apreço pelo Estado brasileiro no que diz respeito às políticas públicas no intuito de promover projetos desenvolvimentistas, sobretudo atrelados à geração de energia. Sob tal fato, nota-se o enorme número de barragens de hidrelétricas estabelecidas em território nacional que, em grande medida, inviabilizam a biodiversidade presente no local, bem como a vida de uma série de povos e comunidades tradicionais. Sobre isso, é possível observar, como bem explorado anteriormente, que a implementação dessas estruturas, a partir do alagamento quilométrico de uma dada área, minam as relações sociais, produtivas e, não raro, o modo de vida dessas populações, assim como impede que a biodiversidade do local permaneça como antes, isto é, como deve ser (SANTOS, 2015; ZUIN; SECCO, 2019).

Nesse sentido, é válido expor que a apresentação do Plano de Energia Elétrica 19872010, promoveu a previsão de uma série de construções de usinas hidrelétricas nos rios da Amazônia. Essas construções demonstraram o interesse da política governamental para essa região, ou seja, submeter a vida dos povos ligados às regiões ribeirinhas à lógica do desenvolvimento que trata as questões a partir do valor econômico que elas podem representar.

\footnotetext{
${ }^{3}$ Aqui cabe salientar que certos autores divergem com relação a tal conceito apresentado, isto é, "energia limpa" à luz das usinas hidrelétricas. Há referências que afirmam que tal acepção caracteriza-se em uma fonte de energia capaz de não lançar poluentes na atmosfera e que, com isso, impacta a natureza apenas nas localidades em que se instala. Entretanto, há autores que dizem que apesar desta energia não estar associada à queima de combustível fóssil, a geração de energia hidrelétrica, supostamente limpa, contribui para a emissão de dióxido de carbono $(\mathrm{CO} 2)$ e metano $(\mathrm{CH} 4)$, gases estes que agravam o aquecimento global.
} 
Com relação a isso, obras como Belo Monte, no Pará, foram construídas e tiveram grandes impactos sobre a vida dessas populações que dependiam, por exemplo, do rio Xingu para a sua sobrevivência e que, lamentavelmente foram obrigadas a se retirarem de suas localidades de origem e começarem uma nova vida, totalmente díspar do habitual, ou melhor, de sua cultura (ZUIN; SECCO, 2019).

A respeito dessa questão, o MAB, surge a partir da urgência dessa problemática, uma vez que a falência do Estado perante essa questão acarreta uma mobilização coletiva com escopo em denunciar os impactos e as mudanças sociais que esses projetos promovem, bem como a violação de direitos humanos que essas populações sofrem durante esse processo. Nesse sentido, a frase "água para vida e não para a morte" ilustra a luta que esse movimento trilha em defesa da proteção dessa população atingida pelos investimentos do setor hidrelétrico, considerado um dos mais importantes para o desenvolvimento da economia, mas que trata esses cidadãos como empecilhos ao desenvolvimento, isto é, ao suposto "progresso".

\section{CONSIDERAÇÕES FINAIS}

Dentre as principais disposições e posicionamentos expressados durante o corpo do trabalho, apesar de diversos avanços conquistados no que diz respeito à garantia dos direitos de povos tradicionais no Brasil, evidencia-se a necessidade de uma maior observância com relação a esses povos, como as populações ribeirinhas, principalmente no que diz respeito a manutenção de seu modo de vida. Acerca disso, a falta de uma postura efetiva de fomento estatal que zele pela salvaguarda deste mesmo povo tradicional, a construção das dantescas obras referidas que minam toda e qualquer relação social e produtiva desta população, além de danificar o ecossistema local, e, hodiernamente, o dificultoso e limitado acesso à saúde por parte desses cidadãos durante a nefasta conjuntura da Covid-19, são retratos do acachapante descaso governamental para com este povo. Estes problemas, em sua origem, possuem raízes históricas como toda e qualquer desigualdade existente no Brasil.

Não obstante, o abandono dessas populações por parte do Estado com a falta de políticas públicas que garantam o cumprimento de seus direitos, as ações de cunho desenvolvimentista que promovem a remoção dos povos dos locais que tradicionalmente ocupam, além da impunidade (em muitos casos) com que crimes ambientais são cometidos nessas áreas, vem contribuindo para o contínuo desmonte das formas de vida desses povos. A esse cenário somaram-se, recentemente, dois fatores agravantes: o plano de (des)governo do presidente Jair Bolsonaro e a pandemia da Covid-19. O primeiro reduzindo ainda mais a atenção 
do Estado às necessidades dos povos ribeirinhos e outros povos tradicionais e, ainda, incentivando atividades econômicas que violem os territórios desses povos, já o segundo, aumentando, em muito, as mortes entre seus integrantes e afetando o acesso a produtos básicos, à comunicação, à saúde e ao comércio.

À luz dessas problemáticas, vislumbra-se o surgimento de um protagonismo encabeçado pela sociedade civil e movimentos sociais, ocupando o papel que, a princípio, caberia ao Estado, além de uma maior mobilização internacional para criar tratados e convenções que buscam assegurar o cumprimento dos direitos dos povos tradicionais. Tal mobilização coletiva da sociedade carrega consigo o escopo de denunciar os impactos das mudanças sociais e ecológicas que a falta de políticas públicas eficazes, bem como a execução de projetos à lógica do desenvolvimento, no qual trata as questões a partir e apenas do ponto de vista atrelado ao valor econômico que elas podem representar, promovem. Isso não tem sido, entretanto, suficiente para frear o desaparecimento desses povos e de seu modo de vida.

Nesse sentido, o presente trabalho procurou evidenciar essas questões em busca de provocar reflexão à sociedade civil. Tamanha provocação tem por objetivo claro expressar a contínua negligência do Estado brasileiro para os povos e comunidades tradicionais. É preciso que, cada vez mais, a população respeite, compreenda e se posicione pelos direitos dos povos tradicionais, a fim de que haja uma pressão contínua sobre os governos para que esses grupos sejam, de fato, atendidos e preservados.

\section{REFERÊNCIAS}

ALVES, Andréia Duarte; JUSTO, José Sterza. Impactos da construção de usinas hidrelétricas na vida de ribeirinhos. Emancipação, v.9, n.2, p. 197-211, 2009. Disponível em: <https://revistas2.uepg.br/index.php/emancipacao/article/view/1065>. Acesso em: 20/04/2021.

BONFÁ NETO, Dorival; SUZUKI, Júlio César. Pesca artesanal na América Latina: pesquisa, conflitos e dilemas, uma revisão bibliográfica sistemática com foco no Brasil e na Colômbia. Mares: Revista de Geografia e Etnociências, v.1, n.1, p. 97-114, 2019. Disponível em: <http://revistamares.com.br/index.php/files/article/view/24>. Acesso em: 18/04/2021.

BRAGA, Pedro Gross Saturnino. Direitos Humanos na perspectiva dos povos tradicionais. Dignidade Re-Vista, v. 1, n. 1, p. 124-132, 2016. Disponível em: <http://periodicos.puc-rio.br/index.php/dignidaderevista/article/view/213 >. Acesso em: 03/04/2021.

BRASIL. Decreto legislativo $n^{\circ} 74$ de 30 de junho de 1977. Aprova o texto da Convenção Relativa à Proteção do Patrimônio Mundial, Cultural e Natural. Disponível em: <https://www2.camara.leg.br/legin/fed/decleg/1970-1979/decretolegislativo-74-30-junho1977-364249-publicacaooriginal-1-pl.html>. Acesso em: 01/04/2021.

BRASIL. Decreto $n^{\circ} 80.978$, de 12 de dezembro de 1977. Promulga a Convenção Relativa à Proteção do Patrimônio Mundial, Cultural e Natural, de 1972. Disponível em: 
$<$ http://portal.iphan.gov.br/uploads/legislacao/DecretoLei_n_80.978_de_12_de_dezembro_de 1977.pdf>. Acesso em: 01/04/2021.

BRASIL. Decreto Legislativo n 2, de 03 de fevereiro de 1994. Aprova o texto do Convenção sobre Diversidade Biológica, assinada durante a Conferência das Nações Unidas sobre Meio Ambiente e Desenvolvimento. Disponível em: $<$ https://www2.camara.leg.br/legin/fed/decleg/1994/decretolegislativo-2-3-fevereiro-1994358280-norma-pl.html>. Acesso em: 25/06/2021.

BRASIL. Decreto n².519, de 16 de março de 1998. Promulga a Convenção sobre Diversidade Biológica. Disponível em: <https://www2.camara.leg.br/legin/fed/decret/1998/decreto-2519-16-marco-1998-437336publicacaooriginal-1-pe.html >. Acesso em: 10/04/2021.

BRASIL. Lei $\mathrm{n}^{\mathbf{o}}$ 10.678, de 23 de maio de 2003. Cria a Secretaria Especial de Políticas de Promoção da Igualdade Racial, da Presidência da República, e dá outras providências. Disponível em: <http://www.planalto.gov.br/ccivil_03/leis/2003/110.678.htm>. Acesso em: 25/04/2021.

BRASIL. Decreto $\mathrm{n}^{\circ}$ 5.051, de 19 de abril de 2004. Promulga a Convenção no 169 da Organização Internacional do Trabalho - OIT sobre Povos Indígenas e Tribais. Disponível em: <http://www.planalto.gov.br/ccivil_03/_ato2004-2006/2004/decreto/d5051.htm>. Acesso em: 20/04/2021.

BRASIL. Decreto $n^{\circ} 6.040$ de 2007. Institui a Política Nacional de Desenvolvimento Sustentável dos povos e comunidades tradicionais. Disponível em: $<$ http://www.planalto.gov.br/ccivil_03/_ato2007-2010/2007/decreto/d6040.htm>. Acesso em $14 / 04 / 2021$.

BRASIL. Lei $\mathrm{n}^{\mathrm{o}} 11.959$ de 29 de junho de 2009. Dispõe sobre a Política Nacional de Desenvolvimento Sustentável da Aquicultura e da Pesca. Disponível em: $<$ http://www.planalto.gov.br/ccivil_03/_ato2007-2010/2009/Lei/L11959.htm>. Acesso em: 09/04/2021.

BRASIL. Lei $\mathrm{n}^{\circ} 12.334$, de 20 de setembro de 2010. Estabelece a Política Nacional de Segurança de Barragens destinadas à acumulação de água para quaisquer usos, à disposição final ou temporária de rejeitos e à acumulação de resíduos industriais, cria o Sistema Nacional de Informações sobre Segurança de Barragens. Disponível em: $<$ http://www.planalto.gov.br/ccivil_03/_ato2007-2010/2010/lei/112334.htm>. Acesso em: 20/04/2021.

BRASIL. Lei $\mathrm{n}^{\circ} 12.608$, de 10 de abril de 2012. Institui a Política Nacional de Proteção e Defesa Civil - PNPDEC; dispõe sobre o Sistema Nacional de Proteção e Defesa Civil SINPDEC e o Conselho Nacional de Proteção e Defesa Civil - CONPDEC; autoriza a criação de sistema de informações e monitoramento de desastres. Disponível em: $<$ http://www.planalto.gov.br/ccivil_03/_ato2011-2014/2012/lei/112608.htm>. Acesso em: 20/04/2021.

CANDIDO, Antonio. Os parceiros do Rio Bonito: Estudo sobre o caipira paulista e a transformação dos seus meios de vida. 11 ed. Rio de Janeiro: Ouro sobre azul, 2010.

CHAGAS, Rodrigo. Os desafios da quarentena para quilombolas, indígenas e ribeirinhos no norte do Pará. Brasil de fato. 2020. Disponível em: $<$ https://www.brasildefato.com.br/2020/05/07/os-desafios-da-quarentena-para-quilombolasindigenas-e-ribeirinhos-no-norte-do-para>. Acesso em: 20/04/2021. 
CONVENÇÃO PARA A PROTEÇÃO DO PATRIMÔNIO MUNDIAL, CULTURAL E NATURAL. Unesco. 1972. Disponível em: <https://whc.unesco.org/archive/conventionpt.pdf>. Acesso em: 10/04/2021.

CONVENÇÃO SOBRE DIVERSIDADE BIOLÓGICA. CDB. 1992. Disponível em: <http://www.inovacao.uema.br/imagens-noticias/files/CDB_72.pdf >. Acesso em: 20/04/2021.

DIEGUES, Antonio Carlos. Conhecimento, práticas tradicionais e a etnoconservação da natureza. Desenvolvimento e meio ambiente, v.50, p.116-126, 2019. Disponível em: $\lfloor$ https://revistas.ufpr.br/made/article/view/66617/38436>. Acesso em: 20/04/2021.

DIEGUES, Antonio Carlos. Aspectos Sócio-Culturais e políticos do uso da água. Plano Nacional de recursos hídricos-Ministério do Meio Ambiente. São Paulo: NUPAUP-USP, 2005. p. 1-15.

DIEGUES, Antonio Carlos; ARRUDA, Rinaldo. Saberes tradicionais e biodiversidade no Brasil. São Paulo/Brasília: Ministério do Meio Ambiente/USP, 2001.

DINIZ, Marcelo Bentes et al. A Amazônia (Legal) brasileira: evidências de uma condição de armadilha da pobreza? Anais do XXXV Encontro Nacional de Economia, Recife, 2007. Disponível em: 〈http://www.anpec.org.br/encontro2007/artigos/A07A090.pdf>. Acesso em: 20/04/2021.

FAO, FOOD AND AGRICULTURE ORGANIZATION OF THE UNITED NATIONS. The state of world fisheries and aquaculture. Roma: FAO, 2020a. Disponível em: <http://www.fao.org/documents/card/en/c/ca9229en/>. Acesso em: 24/04/2021.

FAO, FOOD AND AGRICULTURE ORGANIZATION OF THE UNITED NATIONS. How is COVID-19 affecting the fisheries and aquaculture food systems. Roma: FAO, 2020b. Disponível em: $<$ http://www.fao.org/documents/card/en/c/ca8637en/ $>$. Acesso em: 07/04/2021.

FUNAI. Governo federal e lideranças indígenas discutem medidas de combate à covid-19. 2020. Disponível em: <http://www.funai.gov.br/index.php/comunicacao/noticias/6288governo-federal-e-liderancas-indigenas-discutem-medidas-de-combate-a-covid-19>. Acesso em: 20/09/2020.

GAMA, Abel Santiago; FERNANDES, Tiótrefis Gomes; PARENTE, Rosana Cristina; SECOLI, Silvia Regina. Inquérito de saúde em comunidades ribeirinhas do Amazonas, Brasil. Caderno de Saúde Pública, v. 34, n. 2, 2018. Disponível em: <https://www.scielo.br/j/csp/a/nWyTKM4WRV5Gxr4pSVT4Mnp/?lang=pt>. Acesso em: $20 / 02 / 2021$.

GONÇALVES, Rúben Miranda; DOMINGOS, Isabela Moreira. População ribeirinha no Amazonas e a desigualdade no acesso à saúde. Revista de Estudos Constitucionais, Hermenêutica e Teoria do Direito, v.11, n.1, p. 99-108, 2019. Disponível em: <http://www.revistas.unisinos.br/index.php/RECHTD/article/viewFile/rechtd.2019.111.06/60 747117>. Acesso em: 20/02/2021.

LIFSITCH, Andrezza. Curva de contágio da Covid-19 cresce no AM e doença avança para quase $\mathbf{9 0 \%}$ dos municípios do interior. G1. 2020. Disponível em: $<$ https://g1.globo.com/am/amazonas/noticia/2020/05/07/curva-de-contagio-da-covid-19cresce-no-am-e-doenca-avanca-para-quase-90percent-dos-municipios-do-interior.ghtml> . Acesso em: 20/09/2020.

LITTLE, Paul Elliot. Territórios sociais e povos tradicionais no Brasil: por uma antropologia da territorialidade. Série Antropológica no 322. Brasília, 2002. 
LITTLE, Paul Elliott. Desenvolvimento territorial sustentável: desafios e potencialidades para o século XXI. Guaju, v.1, n.2, p. 127-143, 2015. Disponível em: <https://revistas.ufpr.br/guaju/article/view/45039>. Acesso em: 15/04/2021.

NETO, Joaquim Shiraishi. Direito dos Povos e das Comunidades Tradicionais no Brasil: Declarações, Convenções Internacionais e Dispositivos Jurídicos definidores de uma Política Nacional. Coleção documentos de bolso, nº 1. Manaus, PPGSCA-UFAM/Fundação Ford, 2007. Disponível

em: <https://direito.mppr.mp.br/arquivos/File/DireitodospovosedascomunidadesradicionaisnoBras il.pdf>. Acesso em: 19/04/2021.

OIT, ORGANIZAÇÃO INTERNACIONAL DO TRABALHO. Convenção número 169 da OIT sobre Povos Indígenas e Tribais. Disponível em: <https://www.oas.org/dil/port/1989\%20Conven\%C3\%A7\%C3\%A30\%20sobre\%20Povos\%2 0Ind\%C3\%ADgenas\%20e\%20Tribais\%20Conven\%C3\%A7\%C3\%A30\%20OIT\%20n\%20\% C2\%BA\%20169.pdf>. Acesso em: 24/03/2021.

OLIVEIRA, Saiera Silva; MAGANHINI, Thais Bernardes. Questões socioambientais das populações ribeirinhas do rio Madeira - Rondônia. Revista Interdisciplinar de Direitos Humanos, v. 7, n. 2, p. 137-154, 2019. Disponível em: $<$ https://www3.faac.unesp.br/ridh/index.php/ridh/article/view/715/324>. Acesso em: 05/03/2021.

PAULO, Paula Paiva. 650 mil famílias se declaram 'povos tradicionais' no Brasil. G1. 2019. Disponível em: <https://g1.globo.com/natureza/desafio-natureza/noticia/2019/10/29/650-milfamilias-se-declaram-povos-tradicionais-no-brasil-conheca-os-kalungas-do-maior-quilombodo-pais.ghtml>. Acesso em: 24/04/2021.

PINHEIRO JÚNIOR et al. Atuação de acadêmicos de enfermagem nas ações de enfrentamento da covid-19 em comunidades ribeirinhas do Amazonas: relato de experiência. Revista Eletrônica Acervo Saúde, v.12, n.10, p.1-6, 2020. Disponível em: $<$ https://acervomais.com.br/index.php/saude/article/view/5049/2819>. Acesso em: 10/04/2021.

PORTO GONÇALVES, Carlos Walter; LEFF, Enrique. Political Ecology in Latin America: the Social Re-Appropriation of Nature, the Reinvention of Territories and the Construction of an Environmental Rationality. Desenvolvimento e Meio Ambiente, v. 35, p. 65-88, 2015. Disponível em: https://revistas.ufpr.br/made/article/view/43543. Acesso em: 03/04/2021.

RAMALHO, Emiliano Esterci et al. Disseminação da COVID-19 em cidades e localidades rurais da Amazônia Central. 2020. p.1-18. Disponível em: <https://preprints.scielo.org/index.php/scielo/preprint/view/406/507>. Acesso em: 20/04/2021.

RIBEIRO, Darcy. O povo brasileiro; A formação e o sentido do Brasil. São Paulo: Companhia das letras, 2015.

SANTOS, Maria Corrêa dos. O conceito de "atingido" por barragens-direitos humanos e cidadania. Revista Direito e Práxis, v. 6, n.2, p.113-140, 2015. Disponível em: <https://www.e-publicacoes.uerj.br/index.php/revistaceaju/article/view/12698>. Acesso em: 20/04/2021.

UNESCO. Central Amazon Conservation Complex; World Heritage List. UNESCO, 1999. Disponível em: 〈http://whc.unesco.org/en/list/998/documents>. Acesso em: 19/04/2021.

VALENCIO, Norma Felicidade Lopes da Silva; GONÇALVES, Juliano Costa. Da confiança à fatalidade: colapso de barragens como limite ao paradigma da modernização? Revista Política 
\& Trabalho, v.5, n.25, p.203-222, 2006. Disponível em: <https://periodicos.ufpb.br/index.php/politicaetrabalho/article/view/6746>. Acesso em: $15 / 04 / 2021$.

WEIMANN, Guilherme. Os sentimentos eles nunca vão indenizar: Entrevista com Claides Helga. Movimento dos Atingidos por Barragem. 2013. Disponível em: <https://mab.org.br/2013/11/11/os-sentimentos-eles-nunca-v-indenizar/>. Acesso em: $15 / 04 / 2021$.

ZUIN, Aparecida Luiza Alzira; SECCO, Márcio. Direitos humanos e diversidades em povos tradicionais: apresentação. Revista Interdisciplinar de Direitos Humanos, v.7, n. 2, p.13-18, 2019. Disponível em: 〈https://www3.faac.unesp.br/ridh/index.php/ridh/article/view/708/319>. Acesso em: 19/04/2021.

Artigo recebido em: 7 de maio de 2021.

Artigo aceito em: 13 de agosto de 2021. Artigo publicado em: 13 de setembro de 2021. 